\title{
INVESTIGATION OF EXPERIMENT DATA AND SENSITIVITY COEFFICIENT DATA WITH ARTIFICIAL NEURAL NETWORK IN THE OHMIC HEATING PROCESS FOR SOUR ORANGE JUICE
}

\author{
Mohammad Vahedi Torshizi' ${ }^{1}$, Mohsen Azadbakht*2, Mahdi Kashaninejad ${ }^{3}$ \\ ${ }^{1}$ Department of Bio-System Mechanical Engineering, Gorgan University of Agricultural Sciences and Natural \\ Resources, Gorgan, Iran. \\ ${ }^{2}$ Department of Bio-System Mechanical Engineering, Gorgan University of Agricultural Sciences and Natural \\ Resources, Gorgan, Iran. \\ ${ }^{3}$ Department of Food Science and Technology, Gorgan University of Agricultural Sciences and Natural \\ Resources, Gorgan, Iran. \\ azadbakht@gau.ac.ir
}

https://doi.org/10.34302/crpjfst/2019.11.3.2

\begin{tabular}{ll}
\hline Article history: & ABSTRACT \\
Received: & In this investigation, an ohmic heating system was constructed and applied \\
11 January 2019 & to the heating process at three voltage gradient inputs $(8.33,10.83,13.33 \mathrm{~V} /$ \\
Accepted: & $\mathrm{cm})$ and three percent weight loss sample $(10,20$ and $30 \%)$ compared to \\
10 May 2019 & total weight was selected. During the thermal process, the power \\
Keywords: & consumption, electrical conductivity and coefficient performance system \\
Ohmic heating; & were calculated. All experiments were performed in three replications. An \\
Artificial network; & artificial neural network was used to predict experimental data. In this study \\
Sour orange; & multi-layer perceptron were selected and radial basic function artificial \\
Electrical conductivity. & neural network by 1 hidden layers and 4,8 and 12 neurons hidden layers, \\
& and with two activation function (hyperbolic tangent and sigmoid). The \\
& highest R values were for power consumption (0.998), electrical \\
& conductivity (0.996) and Coefficient performance systems $(0.999)$ in a MLP \\
& network with 8 neuron in hidden layer and sigmoid activation. Also the \\
& fastest network with lowest EPOCH was in a network of 12 neuron. \\
& According to the results obtained for R, MSE and learning cycle, it can be \\
& said that the neural network has ability to predict power consumption, \\
& electrical conductivity and coefficient performance systems to an acceptable \\
& level for ohmic processing.
\end{tabular}

\section{Introduction}

Artificial neural network (ANN) seems very appropriate for the investigation and simulation of the data. ANN is, in fact, a collection of mathematical methods mostly including artificial intelligence and it attempts somehow to imitate human brain. During the past two decades, the neural network has exhibited a very high potential in a great many of the science and engineering areas for its exceptional performance, internal organization and selflearning, overcoming the challenges and high solidity rate. Recently, there has come about an increase in the interests in utilizing neural networks as a modeling tool in agriculture and food industry technologies. Neural networks have been successfully employed in several foodstuff processing technologies such as drying, post-harvest technologies, rheology of the foodstuff, microbial predictions, fermentation and thermal processing (Lu et al., 2010). Artificial neural networks are also considered as most effective tools for processing a large volume of information that was once a 
big challenge in various respects. The development trend of the neural networks is suggestive of the importance of using them for information processing because they have been proved highly successful in data analysis and they have been capable of undergoing development in various grounds. Moreover, the use of neural networks is promising in food production and foodstuff quality processing and evaluation methods wherein old methods of data processing might not provide us with accurate information or be substantially costly. Two important abilities of neural networks, to wit prediction and classification scales, have drawn a large deal of attention. According to the internal competencies of the artificial neural networks, they can be successfully applied in agriculture sector (Hosu, Cristea, \& Cimpoiu, 2014). The artificial neural network is a topic discussed in artificial intelligence and it is an information processor trained using a percentage of input and output data and the system's performance method is stored in its memory(Mazloumzadeh, Alavi, \& Nouri, 2008). Artificial neural networks are trained based on calculations on numerical data or examples. One feature of the neural networks is their ability in extracting the relationships between the inputs and outputs of a process with no need to complex environmental conditions. They are capable of connecting a multidimensional space to another space even if the information is imperfect and erroneous. These characteristics have made them appropriate for the problems related to the estimation and prediction in agriculture and industry and the neural network displays a good efficiency when the relations are nonlinear (Beale \& Jackson, 1998; Menhaj, 2000). Moreover, the artificial neural network (ANN) modeling is widely used in many fields. This method is of high efficiency in solving the complex and non-linear equations in dryers (Özdemir, Aktaş, Şevik, \& Khanlari, 2017). They also researcher used neural network in thermal processes:
Mattar and et al (2004) on modeling thermal conductivity, specific heat, and density of milk with neural network reported that artificial neural networks presented a better prediction capability of specific heat, thermal conductivity, and density of milk than polynomial modeling(Mattar et al., 2004).

Chegini et al. (2007) used predictive process and orange juice from artificial neural network, the results of which showed that the properly trained ANN model was able to produce simultaneously seven outputs, unlike traditional models where one mathematical model was required for each output. Radial Basis Function neural networks were not able well to learn the relationship between the input and output parameters. ANN parameters had a significant effect on learning ability of the ANN models(Chegini, Khazaei, Ghobadian, \& Goudarzi, 2008).

The objective of this research is the power consumption, electrical conductivity and Coefficient performance systems analyses of ohmic processing with three ohmic voltage gradient in order to reduce the weight loss sour orange with new processes. For this purpose, the ANN (multilayer perceptron and radial basic function) was applied to verify the accuracy of the numbers obtained. Additionally, the sensitivity coefficient test was applied to relate the power consumption, electrical conductivity and coefficient performance systems factors to voltage gradient and weight loss percentage.

\section{Materials and methods \\ 2.1 Preparation of the sample}

The oranges were purchased from a garden located in the city of Gorgan, Golestan province. The prepared oranges were washed and split into two halves in the middle and immediately after the purchase in the same condition for all samples (ambient temperature and applied uniform pressure), the manual removal was carried out. 


\subsection{Method of testing}

For this processing was considered one tank and the sample were poured into the ohmic tank and between the two electrodes, and their initial temperature was recorded after stability. After recording the temperature, the voltage was applied to the set and the samples were heated. Three heating gradients of $8.33,10.83$ and $13.33 \mathrm{~V} / \mathrm{cm}$ were selected for the heating process and, using this voltage gradient, $10 \%$ (from $90 \mathrm{~g}$ to $81 \mathrm{~g}$ ), $20 \%$ (from $90 \mathrm{~g}$ to $72 \mathrm{~g}$ ) and $30 \%$ (from $90 \mathrm{~g}$ to $63 \mathrm{~g}$ ), the percentage of the total weight of the samples of sour orange discharged inside the cell is steamed during the heating process. All samples were weighed $90 \mathrm{~g}$ and the temperature of all specimens was $26{ }^{\circ} \mathrm{C}$ to initiate the heating process. In Figure 1, a schematic representation of the heating process and system components is shown.

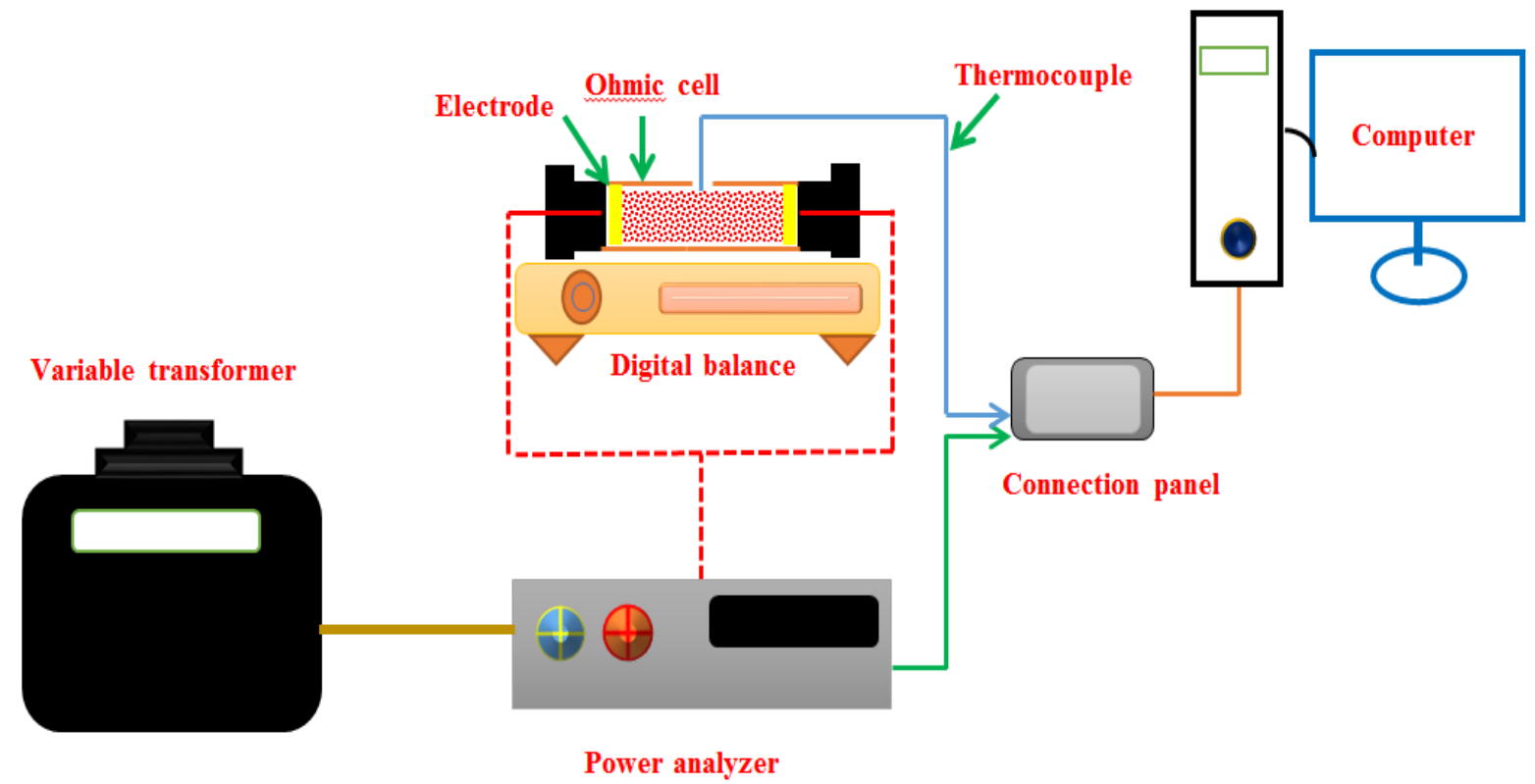

Figure 1. Schematic of equipment used for the ohmic heating process

The experiments were carried out in a homebased heating system. The system specifications used are shown in Table 1. All experiments were carried out at the department of bio systems mechanical engineering, Gorgan University of Agricultural Sciences and Natural Resources

Table 1. The system specifications

\begin{tabular}{|l|l|l|l|}
\hline Length & $6 \mathrm{~cm}$ & Distance electrode & $6 \mathrm{~cm}$ \\
\hline Width & $6 \mathrm{~cm}$ & Power controller & $\begin{array}{l}(3 \mathrm{~kW}, 0-300 \mathrm{~V}, 50 \mathrm{~Hz}, \mathrm{MST}-3, \\
\text { Toyo, Japan }\end{array}$ \\
\hline Height & $3 \mathrm{~cm}$ & Balance accuracy & $0.01 \mathrm{~g}$ \\
\hline Thickness & $0.3 \mathrm{~cm}$ & Electrode Thickness & $0 . \mathrm{cm}$ \\
\hline Electrode & Steel & & \\
\hline
\end{tabular}




$$
\mathrm{P}=\mathrm{VI}=\mathrm{I}^{2} \mathrm{R}
$$

2.3. The equations of the heating process of ohmic

Electrical conductivity was calculated using the resistivity of the samples within the cell geometry used in equation (1)(Castro, Teixeira, Salengke, Sastry, \& Vicente, 2004)( Cappato et al., 2017)

$$
\sigma=R \frac{L}{A}=\frac{L I}{A V}
$$

In this formula, $\sigma=$ the electrical conductivity of the sample L: the distance between the two electrodes (m) from each other, A: the crosssectional area of the plates $\left(\mathrm{m}^{2}\right), \mathrm{V}$ : the input voltage (V), I: the input current (A)

During the heating, the contact surface between the samples and the electrode decreases due to the vapor output, the contact surface can be calculated using the equation below. ( Darvishi, Hosainpour, Nargesi, \& Fadavi, 2015 :

$$
\begin{gathered}
A=\frac{M_{t}}{\rho_{t} L} \\
\rho_{t}=1340-3.26 M_{t}^{2} \\
\mathrm{M}_{\mathrm{t}} \quad \text { Humidity content at any moment }
\end{gathered}
$$

Power consumption was also calculated using formula 4 (Kanjanapongkul, 2017):
In this equation, $\mathrm{P}$ is the power consumption (W)

The energy given to the system in accordance with the relationship provided by icier and Hammers in 2005 is as follows (Srivastav \& Roy, 2014)

$$
\begin{aligned}
& E_{\text {given }}=E_{\text {taken }}+E_{\text {loss }} \\
& \sum(V I t)=m c_{p}\left(T_{f}-T_{i}\right)+E_{\text {loss }}
\end{aligned}
$$

The energy of the system is equal to the sum of the energy needed to increase the temperature of the cell, the energy dissipated to the environment through the displacement and the electrical energy converted to heat. In the above equations, the volatility value was determined and the amperes and time values were calculated by the software. The initial temperature and final temperature of the orange water were measured by a thermometer and the mass of water in the orange water was calculated by the balance. The system performance coefficient is given by the energy ratio taken by the system to the energy and calculated from the following equation (Darvishi, Khostaghaza, \& Najafi, 2013.)

$$
\begin{aligned}
S P C= & \frac{E_{\text {taken }}}{E_{\text {given }}} \\
& S P C=\frac{m c_{p}\left(T_{f}-T_{i}\right)}{\sum(V I t)}
\end{aligned}
$$

In this formula, the energy given to system $(j), T_{f}$ is the final temperature $(\mathrm{C})$, Etaken energy taken from the system (j), $T_{i}$ input temperature, $E_{\text {loss }}$, the energy lost in the system (j), t (s), SPC is the coefficient of performance system, $\mathrm{m}$ is the mass of the sample $(\mathrm{kg})$. 


\subsection{Artificial Neural Network Modeling}

In this research, the artificial multilayer perceptron (MLP) and radial basic function (RBF) neural network were used for modeling the Investigating sour orange components during voltage and percent decrease mass different to predict electrical conductivity by one hidden layer and 4,8 , and 12 neurons using the Neuro-Solution 5 software. Hyperbolic tangent and sigmoid activation functions (Equation 3,4), which are the most common type of activation functions, were used in the in hidden input and output layer. In this paper, the Levenberg-Marquardt algorithm was used to learn the network(Taheri-Garavand, Karimi, Karimi, Lotfi, \& Khoobbakht, 2018). Additionally, $70 \%$ of the data were used for training, $10 \%$ of them were used for network evaluation (Validating Data), and 20\% of the data were used for testing the network (Testing data) (Table 3). The voltage, decreasing mass value, current input and ohmic time as network inputs and power consumption, electrical conductivity and Coefficient performance systems were the considered network outputs. Five repetitions were considered to achieve the minimum error rate and maximum network stability as a mean of 5000 Epoch for the network. Error was estimated using algorithm with back propagation error. Statistical parameters including, Root Mean Square Error (RMSE), $\mathrm{R}^{2}$, and Mean Absolute Error (MAE) were calculated for inputs and relationships were calculated using the formulas shown in Table 2.

Table 2. Neural Network Relationships

\begin{tabular}{|c|c|c|}
\hline Formula & $\begin{array}{c}\text { Formula } \\
\text { Number }\end{array}$ & Reference \\
\hline Tanh $=\frac{e^{x}-e^{-x}}{e^{x}+e^{-x}}$ & $(8)$ & $\begin{array}{c}\text { (Soleimanzadeh, Hemati, } \\
\text { Yolmeh, \& Salehi, 2015) }\end{array}$ \\
\hline $\mathrm{Sig}=\frac{1}{1+e^{-x}}$ & $(9)$ & $\begin{array}{c}\text { (F. Salehi, Gohari } \\
\text { Ardabili, Nemati, \& Latifi } \\
\text { Darab, 2017) }\end{array}$ \\
\hline $\mathrm{R}^{2}=1-\frac{\sum_{i=1}^{n}\left(P_{i}-O_{i}\right)^{2}}{\left(P_{i}-O\right)^{2}}$ & $(10)$ & $\begin{array}{c}\text { (Azadbakht, Torshizi, \& } \\
\text { Ziaratban, 2016) }\end{array}$ \\
\hline $\mathrm{r}=\sqrt{1-\frac{\sum_{i=1}^{n}\left(P_{i}-O_{i}\right)^{2}}{\left(P_{i}-O\right)^{2}}}$ & $(11)$ & $\begin{array}{c}\text { (Fakhreddin Salehi \& } \\
\text { Razavi, 2012) }\end{array}$ \\
\hline $\mathrm{RMSE}=\sqrt{\sum_{i=1}^{n} \frac{\left(P_{i}-O_{i}\right)^{2}}{n}}$ & $(12)$ & $\begin{array}{c}\text { (B. Khoshnevisan, Sh. } \\
\text { Rafiee, M. Omid, 2013) }\end{array}$ \\
\hline $\mathrm{MAE}=\frac{\sum_{i=1}^{n}\left|P_{i}-O_{i}\right|}{n}$ & $(13)$ & $\begin{array}{c}\text { (Azadbakht, Aghili, } \\
\text { Ziaratban, \& Vehedi } \\
\text { Torshizi, 2017) }\end{array}$ \\
\hline
\end{tabular}


Torshizi et al. /Carpathian Journal of Food Science and Technology 2019,11(3),15-27

Table 3. Optimization values for artificial neural network parameters

\begin{tabular}{|c|c|c|c|c|c|c|}
\hline $\begin{array}{c}\text { Number of } \\
\text { hidden layers }\end{array}$ & $\begin{array}{c}\text { Learning } \\
\text { rule }\end{array}$ & $\begin{array}{c}\text { Type of activation } \\
\text { function }\end{array}$ & $\begin{array}{c}\text { The } \\
\text { number of } \\
\text { hidden } \\
\text { layer } \\
\text { neurons }\end{array}$ & $\begin{array}{c}\text { Testing } \\
\text { data \% }\end{array}$ & $\begin{array}{c}\text { Validating } \\
\text { data } \%\end{array}$ & $\begin{array}{c}\text { Training } \\
\text { data } \%\end{array}$ \\
\hline 1 & $\begin{array}{c}\text { Levenberg } \\
\text { Marquardt }\end{array}$ & $\begin{array}{c}\text { Hyperbolic tangent } \\
\text { and sigmoid }\end{array}$ & 4 & $20 \%$ & $10 \%$ & $70 \%$ \\
\hline 1 & $\begin{array}{c}\text { Levenberg } \\
\text { Marquardt }\end{array}$ & $\begin{array}{c}\text { Hyperbolic tangent } \\
\text { and sigmoid }\end{array}$ & 8 & $20 \%$ & $10 \%$ & $70 \%$ \\
\hline 1 & $\begin{array}{c}\text { Levenberg } \\
\text { Marquardt }\end{array}$ & $\begin{array}{c}\text { Hyperbolic tangent } \\
\text { and sigmoid }\end{array}$ & 12 & $20 \%$ & $10 \%$ & $70 \%$ \\
\hline
\end{tabular}

\section{Results and discussions}

For to predict power consumption, electrical conductivity and coefficient performance systems, MLP and RBF neural network model were used. As lower error value was obtained by using the hyperbolic tangent and sigmoid activation function, this type of function was selected as the activation function in the hidden layer and the output. Based on the test method, $70 \%$ of the data were used for training and the network could learn the relationships between inputs and outputs well and $20 \%$ of the data were used to test the network and $10 \%$ of the data were used to Cross Validation network. The value of Mean squared error, Normalized Mean squared error, Mean absolute error, Correlation coefficient are shown Table 4.The results showed that best neural network for 4 neurons in the hidden layer was in tangent hyperbolic activation function and MLP network for power consumption $(\mathrm{R}=0.991-\mathrm{MSE}=91.419)$, and for Coefficient performance systems $(\mathrm{R}=0.9832$ $0.0003)$ and best value for electrical conductivity $(\mathrm{R}=0.9164-\mathrm{MSE}=0.0072)$ was in RBF network with tangent hyperbolic and sigmoid. Also for neural network with 8 neurons in hidden layer, Sigmoid activation function and MLP network have best amount for power consumption $(\mathrm{R}=0.99832-\mathrm{MSE}=3.5 \mathrm{E}+1)$, electrical conductivity $\quad(\mathrm{R}=0.9963-$ MSE=3.1E-4) and Coefficient performance systems $\quad(\mathrm{R}=0.99963 \quad-7.8 \mathrm{E}-5)$. In neural network with 12 neuron in hidden layer were best amount $\mathrm{R}=0.9996,0.9782,0.999$ for power consumption, electrical conductivity and coefficient performance systems in tangent hyperbolic, respectively and best amount for MSE were $18.800, \quad 0.00089, \quad 0.00001$ respectability in MLP network and tangent hyperbolic tangent activation function. In total MLP network with 8 neuron in hidden layer and sigmoid activation function have best amount $R$ and MSE for power consumption, electrical conductivity and coefficient performance systems. The results showed in table 4 . According to MSE and $\mathrm{R}$ value, network 8 neuron in hidden layer was best network for predication power consumption, electrical conductivity and Coefficient performance systems value, because this network has lowest MSE and highest R. Table 5 shows the best network between input data and the data simulated by the network for each of the neurons in the hidden layer. Smaller epochs suggest that the number of neurons in the layer successfully learned by the neural network compared to other neurons. As shown in table 5, the fastest learning speed network for predicting data with sigmoid activation function and tangent hyperbolic were in network by 12 neuron in hidden layer and RBF network by 795 and 115 EPOCH and RUN 1 for training, respectability. Also according to result in table 5 all network created by RBF has Lowest EPOCH than MLP network. But according to result in table 4, lowest MSE and R was in MLP network, sigmoid and tangent 
hyperbolic activation in 8 and 12 neuron in hidden layer respectively, so the best EPOCH and RUN are 1093-1 for 8 neuron in hidden layer and 795-1for 12 neuron in hidden layer. In total speed training for tangent activation function is highest than sigmoid activation function. Also result for cross validation showed in table 4 for data experiment. The results of the sensitivity analysis for power consumption, electrical conductivity and Coefficient performance systems are shown in Figure 2, 3, 4. Based on this figures, the highest sensitivity for training data were obtained for the Voltage gradin and weight loss percentage in the hidden layers with 8 neurons and sigmoid activation in
MLP network and highest sensitivity process time and input current for electrical conductivity and Coefficient performance systems were in hidden layer 8,12 and hyperbolic tangent, sigmoid activitaion function and RBF, MLP, respectivity. overall, the voltage gradient sensitivity was higher than the other three inputs, meaning the voltage had a greater effect on power consumption, electrical conductivity and Coefficient performance systems. Also, the sensitivity coefficient of the process time and the input current are exactly the same for power consumption, electrical conductivity and Coefficient performance systems.

Table 5. Some of the best MLP and RBF neural network topologies to predict test value

\begin{tabular}{|c|c|c|c|c|c|c|c|}
\hline \multicolumn{6}{|c|}{ Sigmoid } & & \\
\hline \multicolumn{2}{|c|}{12} & \multicolumn{2}{|c|}{8} & \multicolumn{2}{|c|}{4} & & \\
\hline MLP & RBF & MLP & RBF & MLP & RBF & & \\
\hline 795 & 695 & 4377 & 1093 & 4407 & 1934 & Training & \multirow{2}{*}{ ЕРОСН } \\
\hline 7 & 5 & 215 & 73 & 11 & 10 & Cross Validation & \\
\hline 1 & 1 & 1 & 1 & 5 & 1 & Training & \multirow{2}{*}{ RUN } \\
\hline 4 & 1 & 1 & 3 & 5 & 5 & Cross Validation & \\
\hline \multicolumn{6}{|c|}{ Tangent hyperbolic } & & \\
\hline \multicolumn{2}{|c|}{12} & \multicolumn{2}{|c|}{8} & \multicolumn{2}{|c|}{4} & & \\
\hline MLP & RBF & MLP & RBF & MLP & RBF & & \\
\hline 157 & 115 & 4999 & 457 & 5000 & 500 & Training & ЕDOCH \\
\hline 32 & 21 & 25 & 6 & 15 & 7 & Cross Validation & EFUCh \\
\hline 1 & 1 & 1 & 1 & 4 & 1 & Training & $\mathbf{R U N}$ \\
\hline 3 & 4 & 3 & 2 & 4 & 3 & Cross Validation & neiv \\
\hline
\end{tabular}


Table 4. Error values in predicting experimental data using optimal artificial neural network

\begin{tabular}{|c|c|c|c|c|c|c|c|c|c|c|c|c|c|}
\hline \multicolumn{12}{|c|}{ Power consumption } & & \\
\hline \multicolumn{3}{|c|}{$\mathbf{R}$} & \multicolumn{3}{|c|}{ MAE } & \multicolumn{3}{|c|}{ NMSE } & \multicolumn{3}{|c|}{ MSE } & & \\
\hline 12 & 8 & 4 & 12 & 8 & 4 & 12 & 8 & 4 & 12 & 8 & 4 & & \\
\hline 0.9534 & 0.99832 & 0.9815 & 14.97 & 4.7526 & 16.1328 & 0.1019 & $\begin{array}{c}8.2 \mathrm{E}- \\
03\end{array}$ & 0.0978 & 481.45 & $3.5 \mathrm{E}+01$ & 473.2174 & \multirow[t]{2}{*}{$\mathrm{S}$} & MLP \\
\hline 0.91236 & 0.9690 & 0.9636 & 29.65 & 10.37 & 17.24 & 0.863 & 0.0639 & 0.0845 & 580.65 & 309.14 & 413.43 & & RBF \\
\hline 0.99683 & 0.99288 & 0.991 & 2.519 & 4.84 & 6.636 & 0.00649 & 0.02 & 0.019 & 18.800 & 78.30 & 91.419 & \multirow{2}{*}{$\mathrm{T}$} & MLP \\
\hline 0.9822 & 0.9827 & 0.9655 & 14.01 & 7.3861 & 16.2073 & 0.0812 & 0.0370 & 0.0855 & 279.28 & 107.7434 & 388.5924 & & RBF \\
\hline \multicolumn{12}{|c|}{ Electrical conductivity } & & \\
\hline 0.8215 & 0.99633 & 0.9157 & 0.0762 & 0.0117 & 0.0696 & 0.3808 & $\begin{array}{c}1.1 \mathrm{E}- \\
02\end{array}$ & 0.1937 & 0.0116 & $3.1 \mathrm{E}-04$ & 0.0077 & \multirow[t]{2}{*}{$\mathrm{S}$} & MLP \\
\hline 0.7936 & 0.9465 & 0.8258 & 0.156 & 0.0579 & 0.0838 & 0.456 & 0.1222 & 0.3323 & 0.0793 & 0.0050 & 0.0130 & & RBF \\
\hline 0.97824 & 0.94909 & 0.883 & 0.01512 & 0.04 & 0.076 & 0.04368 & 0.10 & 0.227 & 0.00089 & 0.0036 & 0.009 & \multirow{2}{*}{$\mathrm{T}$} & MLP \\
\hline 0.5661 & 0.9088 & 0.9164 & 0.2582 & 0.0589 & 0.0670 & 4.7372 & 0.2098 & 0.1911 & 0.0864 & 0.0059 & 0.0072 & & RBF \\
\hline \multicolumn{12}{|c|}{ Coefficient performance systems } & & \\
\hline 0.97813 & 0.999750 & 0.9799 & 0.01632 & 0.0059 & 0.0144 & 0.04714 & $\begin{array}{c}\text { 7.7E- } \\
03\end{array}$ & 0.0403 & 0.00044 & $7.8 \mathrm{E}-05$ & 0.0004 & \multirow[t]{2}{*}{$\mathrm{S}$} & MLP \\
\hline 0.9336 & 0.9936 & 0.9832 & 0.0296 & 0.0093 & 0.0143 & 0.089 & 0.0133 & 0.0357 & 0.00245 & 0.0001 & 0.0003 & & RBF \\
\hline 0.99963 & 0.98228 & 0.973 & 0.00187 & 0.01 & 0.020 & 0.00077 & 0.04 & 0.060 & 0.00001 & 0.0002 & 0.001 & \multirow{2}{*}{$\mathrm{T}$} & MLP \\
\hline 0.9916 & 0.9851 & 0.9375 & 0.0228 & 0.0122 & 0.0265 & 0.0822 & 0.0314 & 0.1229 & 0.0008 & 0.0003 & 0.0010 & & RBF \\
\hline
\end{tabular}



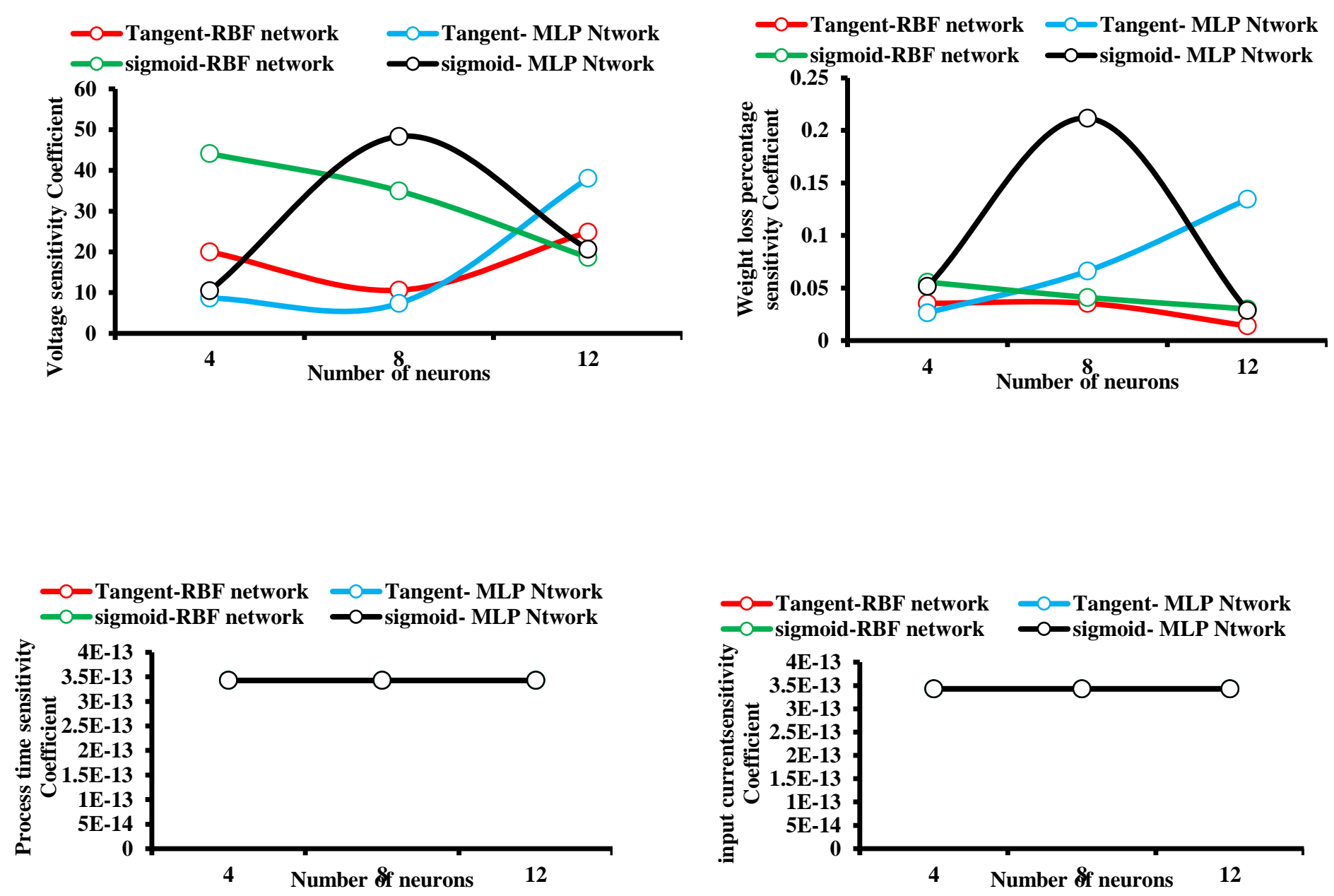

Figure 2. Sensitivity coefficient power consumption 

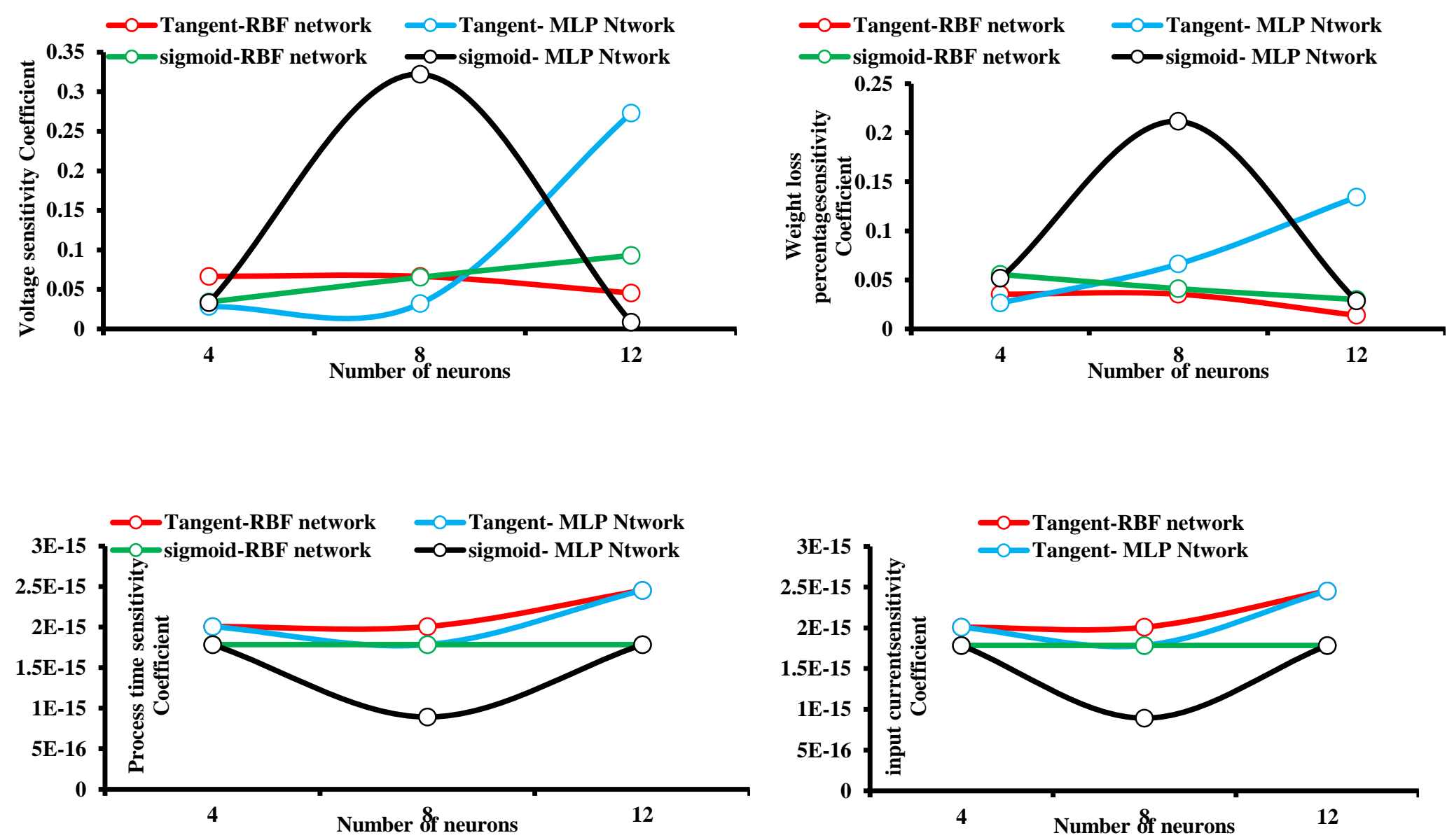

Figure 3. Sensitivity coefficient conductive electrical 

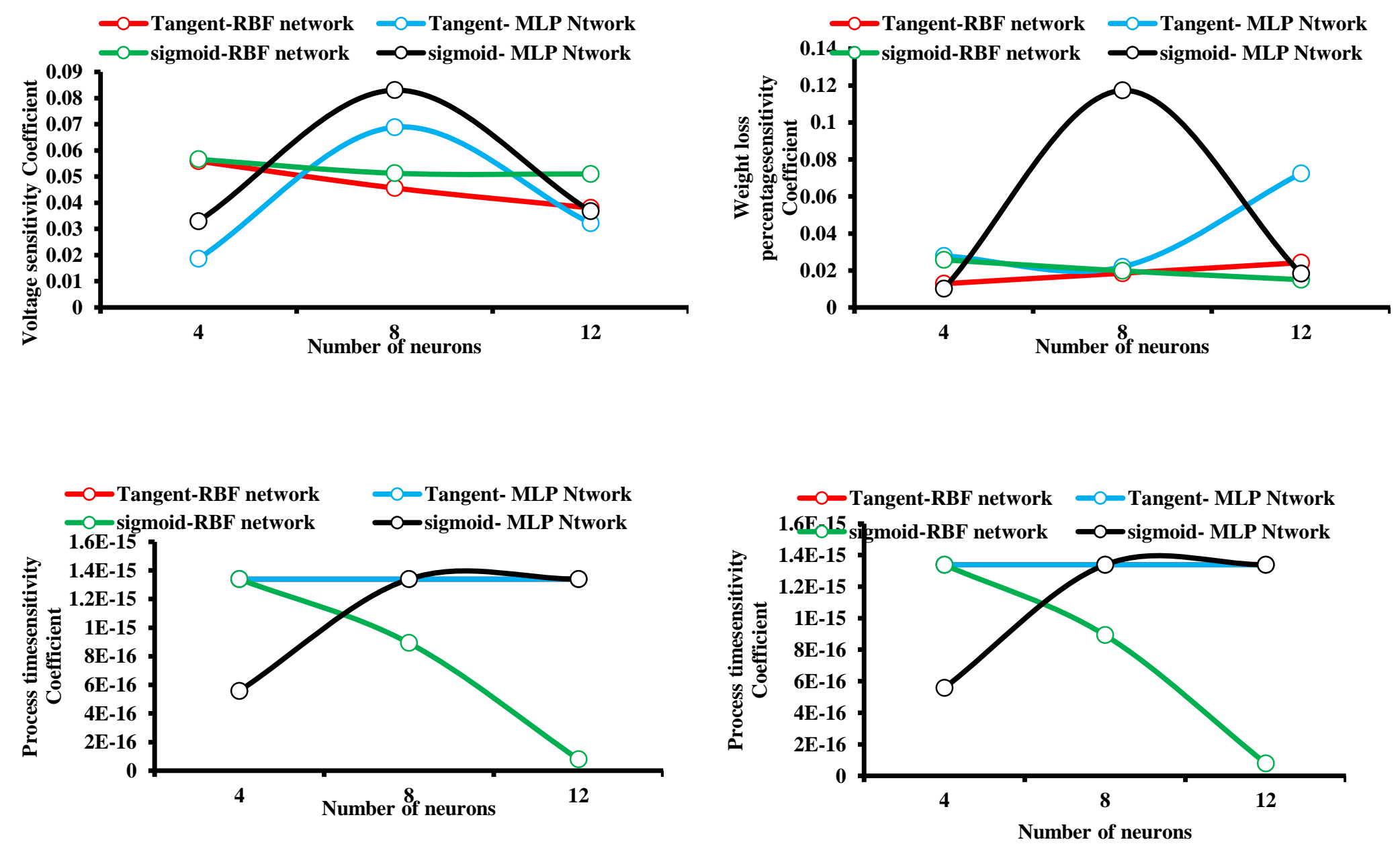

Figure 4. Sensitivity coefficient, coefficient performance systems 


\section{Conclusion}

For power consumption, electrical conductivity and performance system, the best $\mathrm{R}$ value in the MLP network with 8 neurons in the hidden layer was the sigmoid activation function, But for power consumption and system efficiency, Sigmoid activation functions and tangent have been able to show $R$ values in RBF and MLP networks, These values were good for all three numbers of input neurons for the network. But for electrical conductivity, the network with 12 neurons, and especially the RBF network, has not shown satisfactory results.

For power consumption, electrical conductivity and performance system were the lowest MSE in a network of 8 neurons, The MSE values for both the hyperbolic and sigmoid tangency activation function were lower for both the MLP and RBF networks than for the two networks with 4 and 12 neurons, which suggests a better formation of the network with 8 neurons.

According to the results of the network learning speed, as the number of neurons in the hidden layer has increased, the speed of network learning has increased to simulate data, and the fastest network with lowest EPOCH was in a network of 12 neuron. Also, the hyperbolic tangent activation function has a faster speed in network training than sigmoid activation function.

The sensitivity coefficient for the Voltage gradient relative to the other parameters of the network input has a greater effect on the power consumption, the electrical conductivity coefficient, and the coefficient performance of the system.

\section{References}

Azadbakht, M., Aghili, H., Ziaratban, A., \& Vehedi Torshizi, M. (2017). Application of artificial neural network method to exergy and energy analyses of fluidized bed dryer for potato cubes. Energy, 120, 947-958. https://doi.org/10.1016/j.energy.2016.12.00 6
Azadbakht, M., Torshizi, M. V., \& Ziaratban, A. (2016). Application of Artificial Neural Network ( ANN ) in predicting mechanical properties of canola stem under shear loading. Agricultural Engineering International: CIGR Journal, 18(5), 413424.

B. Khoshnevisan, Sh. Rafiee, M. Omid, M. Y. (2013). Prediction of environmental indices of Iran wheat production using artificial neural networks. International Journal of Energy and Environment, 4(2), 339-348.

Beale, R., \& Jackson, T. (1998). Neural Computing: An Introduction. London, UK, Institude of Physics Publishing, Bristol BSI 6BE. https://doi.org/008.3

Cappato, L. P., Ferreira, M. V. S., Guimaraes, J. T., Portela, J. B., Costa, A. L. R., Freitas, M. Q., ... Cruz, A. G. (2017). Ohmic heating in dairy processing: Relevant aspects for safety and quality. Trends in Food Science and Technology, 62(February), 104-112. https://doi.org/10.1016/j.tifs.2017.01.010

Castro, I., Teixeira, J. A., Salengke, S., Sastry, S. K., \& Vicente, A. A. (2004). Ohmic heating of strawberry products: Electrical conductivity measurements and ascorbic acid degradation kinetics. Innovative Food Science and Emerging Technologies, 5(1), 27-36.

https://doi.org/10.1016/j.ifset.2003.11.001

Chegini, G. R., Khazaei, J., Ghobadian, B., \& Goudarzi, A. M. (2008). Prediction of process and product parameters in an orange juice spray dryer using artificial neural networks. Journal of Food Engineering, 84(4), 534-543.

Darvishi, H., Hosainpour, A., Nargesi, F., \& Fadavi, A. (2015). Exergy and energy analyses of liquid food in an Ohmic heating process: A case study of tomato production. Innovative Food Science and Emerging Technologies, 31, 73-82. https://doi.org/10.1016/j.ifset.2015.06.012

Darvishi, H., Khostaghaza, M. H., \& Najafi, G. (2013). Ohmic heating of pomegranate juice: Electrical conductivity and $\mathrm{pH}$ 
change. Journal of the Saudi Society of Agricultural Sciences, 12(2), 101-108. https://doi.org/10.1016/j.jssas.2012.08.003

Hosu, A., Cristea, V. M., \& Cimpoiu, C. (2014). Analysis of total phenolic, flavonoids, anthocyanins and tannins content in Romanian red wines: Prediction of antioxidant activities and classification of wines using artificial neural networks. Food Chemistry, $\quad 150, \quad 113-118$. https://doi.org/10.1016/j.foodchem.2013.10 .153

Kanjanapongkul, K. (2017). Rice cooking using ohmic heating: Determination of electrical conductivity, water diffusion and cooking energy. Journal of Food Engineering, 192, $1-10$.

https://doi.org/10.1016/j.jfoodeng.2016.07. 014

Lu, H., Zheng, H., Lou, H., Jiang, L., Chen, Y., \& Fang, S. (2010). Using neural networks to estimate the losses of ascorbic acid, total phenols, flavonoid, and antioxidant activity in asparagus during thermal treatments. Journal of Agricultural and Food Chemistry, 58(5), 2995-3001. https://doi.org/10.1021/jf903655a

Mattar, H. L., Minim, L. A., Coimbra, J. S. R., Minim, V. P. R., Saraiva, S. H., \& TelisRomero, J. (2004). Modeling thermal conductivity, specific Heat, and density of milk: A neural network approach. International Journal of Food Properties, 7(3), 531-539. https://doi.org/10.1081/JFP200032964

Mazloumzadeh, S. ., Alavi, S. ., \& Nouri, M. (2008). Comparison of Artificial Neural and Wavelet Neural Networks for Prediction of Barley Breakage in Combine Harvester. Journal of Agriculture, 10(2), 181-195.

Menhaj, M. (2000). Foundation of Artifitioal Neural Networks. Amir Kabir univercity.

Özdemir, M. B., Aktaş, M., Şevik, S., \& Khanlari, A. (2017). Modeling of a convective-infrared kiwifruit drying process. International Journal of Hydrogen Energy, 42(28), 18005-18013. https://doi.org/10.1016/j.ijhydene.2017.01. 012

Salehi, F. 1, Gohari Ardabili, A., Nemati, A. 2, \& Latifi Darab, R. (2017). Modeling of strawberry drying process using infrared dryer by genetic algorithm-artificial neural network method. Journal Food Science and Technology, 14, 105-114.

Salehi, F., \& Razavi, S. M. A. (2012). Dynamic modeling of flux and total hydraulic resistance in nanofiltration treatment of regeneration waste brine using artificial neural networks. Desalination and Water Treatment, 41(1-3), 95-104. https://doi.org/10.1080/19443994.2012.664 683

Soleimanzadeh, B., Hemati, L., Yolmeh, M., \& Salehi, F. (2015). GA-ANN and ANFIS models and salmonella enteritidis inactivation by ultrasound. Journal of Food Safety, 35(2), 220-226. https://doi.org/10.1111/jfs. 12174

Srivastav, S., \& Roy, S. (2014). Changes in electrical conductivity of liquid foods during ohmic heating. International Journal of Agricultural and Biological Engineering, 7(5), 133-138. https://doi.org/10.3965/j.ijabe.20140705.01 5

Taheri-Garavand, A., Karimi, F., Karimi, M., Lotfi, V., \& Khoobbakht, G. (2018). Hybrid response surface methodology-artificial neural network optimization of drying process of banana slices in a forced convective dryer. Food Science and Technology International, 24(4), 277-291. https://doi.org/10.1177/1082013217747712 